\title{
Intracranial Carotid Artery Occlusion with Telangiectasia (Moyamoya Disease) Associated with Persistent Primitive Trigeminal Artery -Case Report-
}

\author{
En-Chow TAN, Takuji TAKAGI and Hajime NAGAI* \\ Department of Neurosurgery, Nagoya City Higashi General Hospital, Nagoya; \\ *Department of Neurosurgery, Nagoya City University Medical School, Nagoya
}

\begin{abstract}
A 35-year-old female presented with moyamoya disease coincidentally associated with a persistent primitive trigeminal artery (PPTA). Bilateral encephalo-duro-arterio-synangiosis was performed and the postoperative course was uneventful. Moyamoya disease and PPTA might have a congenital origin, but moyamoya disease may be promoted by a PPTA. The hemodynamics of PPTA during progressive occlusive change in the internal carotid artery in moyamoya disease should be re-evaluated to determine its function in the development of moyamoya vessels.
\end{abstract}

Key words: carotid-basilar anastomosis, moyamoya disease, persistent primitive trigeminal artery

\section{Introduction}

The primitive trigeminal artery is one of the presegmental dorsal arteries responsible for the carotidbasilar anastomosis during embryonic development. It is the last to be obliterated, between the 3 and 6 $\mathrm{mm}$ stages of embryonic development. Angiographic studies on intracranial lesions show its persistence has a higher incidence $(0.1-0.3 \%)$ than any other presegmental dorsal vessels. ${ }^{9}$ Some intracranial lesions occur coincidentally with the persistent primitive trigeminal artery (PPTA), but no pathological significance has been shown. ${ }^{1,3,9)}$ However, PPTA is rarely associated with moyamoya disease, with only seven cases previously reported. ${ }^{4,6,8,10,12)}$ Here, we describe another case of moyamoya disease in whom angiograms demonstrated a PPTA.

\section{Case Report}

This 35-year-old female suddenly lost consciousness for several minutes, and was admitted to a local

Received January 11, 1991; Accepted April 24, 1991 hospital without neurological deficits. Cerebral angiograms demonstrated the characteristic features of moyamoya disease. She was referred to our hospital for surgical intervention.

Neurological examination on admission revealed no abnormal findings. Right internal carotid angiograms showed complete occlusion of the internal carotid artery beyond the supraclinoid segment with telangiectasia. A PPTA branched from the $\mathrm{C}_{4}$ portion of the internal carotid artery and terminated at the midportion of the basilar artery. Moyamoya vessels originated from the internal carotid and posterior choroidal arteries (Fig. 1). Left internal carotid angiograms revealed the occluded portion at the same level as on the right. Moyamoya vessels originated from the anterior choroidal artery (Fig. 2). Vertebral angiograms showed no hypoplasia in the vertebrobasilar system proximal to the junction with the PPTA.

Bilateral encephalo-duro-arterio-synangiosis was performed and the postoperative course was uneventful. She was discharged 2 weeks after the operation. Selective external carotid angiograms 7 months later showed the middle cerebral arteries filled through the leptomeningeal anastomosis from the superficial tem- 

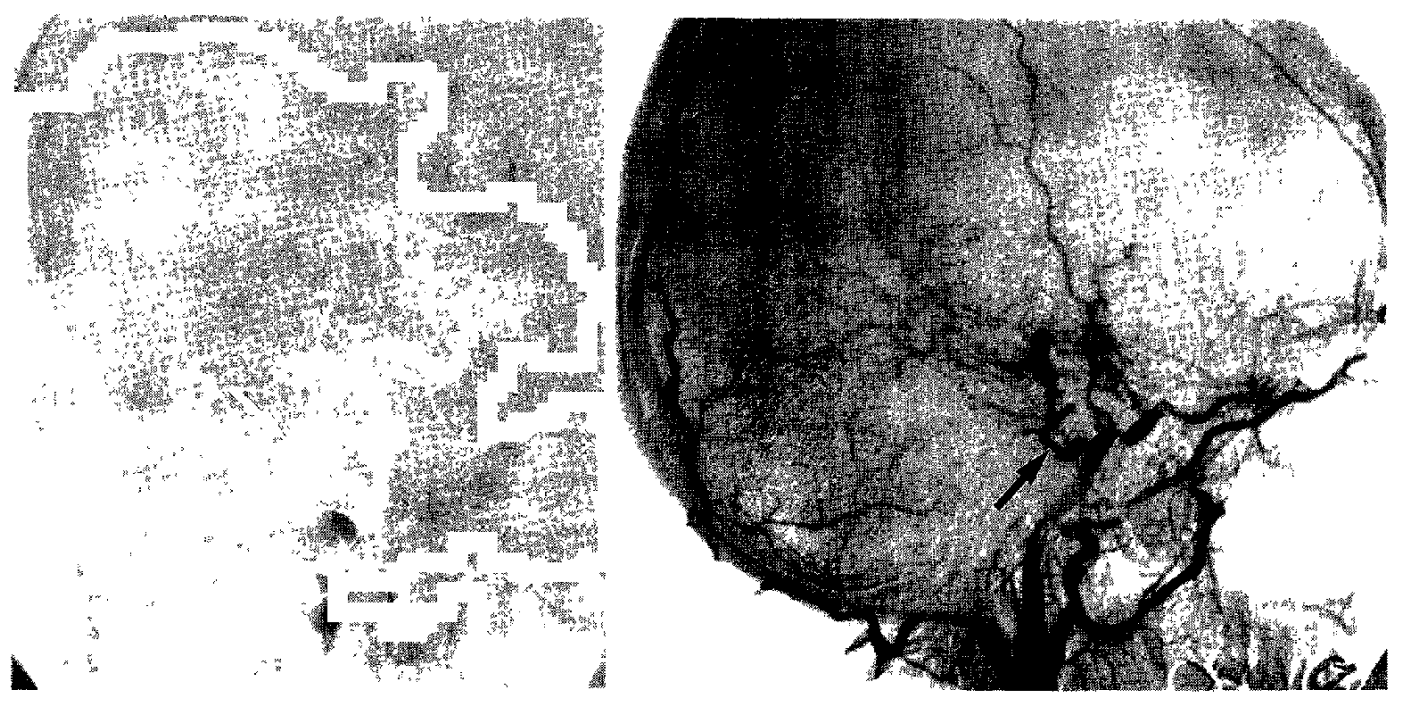

Fig. 1 Right carotid angiograms, anteroposterior (left) and lateral (right) views, showing supraclinoid occlusion of the internal carotid artery and moyamoya vessels originating from the internal carotid and the posterior choroidal arteries. The PPTA is visible (arrow).

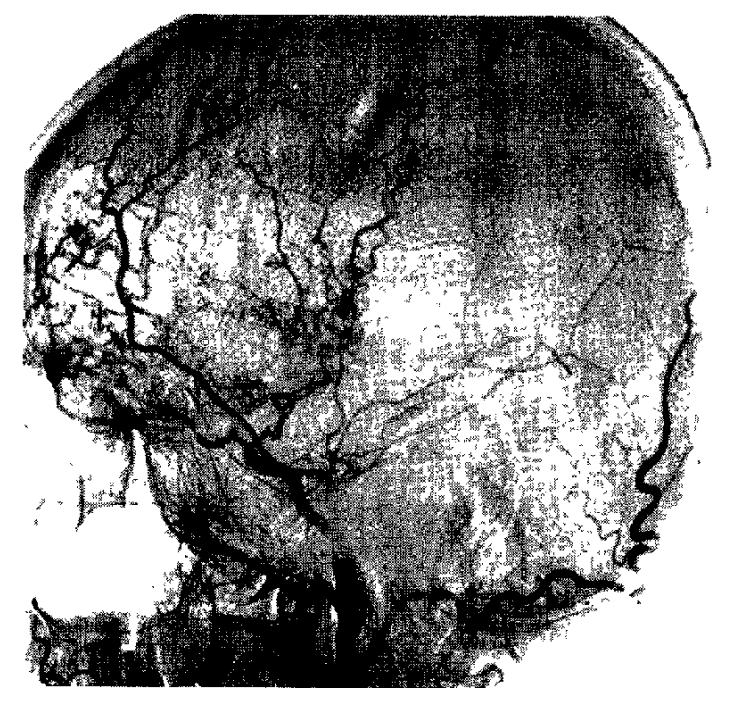

Fig. 2 Left carotid angiogram, lateral view, showing the characteristic findings of moyamoya disease.

poral arteries. Magnetic resonance images 13 months postoperatively showed watershed infarction of the right anterior and middle cerebral arteries. However, symptoms did not recur and she was neurologically normal.

\section{Discussion}

Table 1 summarizes the eight reported cases of moyamoya or moyamoya-like disease associated with PPTA. All patients were Japanese and there was no sex predominance. Except for two cases, which were not described in detail, ${ }^{4)}$ the clinical manifestations were the same as in moyamoya disease. Intracranial hematoma occurs mainly in adults, while ischemic change occurs in children. Computed tomographic (CT) scans showed cerebral hemorrhage or ischemic lesions ipsilateral to the PPTA in only two cases. The cause of the clinical symptoms in these two was thought to be moyamoya disease rather than the PPTA. An incidental aneurysm occurred in only one case.

At the 5-6 mm stage of embryonic development, the posterior communicating artery gradually takes over the function of the arteries forming the carotidbasilar anastomosis. Therefore, similar hemodynamics probably occur in the PPTA and the posterior communicating artery. Both carotid and vertebral angiography may demonstrate a PPTA. ${ }^{57} \mathrm{Huber}^{5}$ suggested that the pressure in the carotid and vertebral arteries may be identical and blood flow in either direction may occur under certain conditions. Nielsen and Johnson ${ }^{11)}$ found that stenosis of the carotid bifurcation caused filling of the PPTA by vertebral angiography only, and the blood flow of the vertebrobasilar system was directed into the carotid system through the PPTA. However, intracranial carotid stenosis beyond the supraclinoid segment might cause the diversion of blood from the carotid system, thus contributing to the clinical manifestation of ischemia. Huber ${ }^{5)}$ emphasized that ischemia in the cerebrum might worsen if blood steal- 
Table 1 Summary of eight cases of moyamoya or moyamoya-like disease with PPTA

\begin{tabular}{|c|c|c|c|c|c|}
\hline Author (Year) & $\begin{array}{l}\text { Age } / \\
\text { Sex }\end{array}$ & $\begin{array}{l}\text { Side of } \\
\text { PPTA }\end{array}$ & Clinical symptoms & CT findings & Angiographic findings \\
\hline \multirow[t]{2}{*}{$\begin{array}{l}\text { Handa and Handa } \\
\qquad(1972)^{4)}\end{array}$} & - & rt & - & - & - \\
\hline & - & - & - & - & - \\
\hline $\begin{array}{l}\text { Otsuki et al. } \\
(1982)^{12)}\end{array}$ & $51 / \mathrm{M}$ & It & rt hemiparesis & $\begin{array}{l}\text { subcortical hematoma in } \\
\text { It temporoparietal lobe }\end{array}$ & $\begin{array}{l}\text { bil ICA occlusion with } \\
\text { moyamoya vessels, } \\
\text { arteriosclerotic change }\end{array}$ \\
\hline \multirow[t]{2}{*}{$\begin{array}{l}\text { Kwak and Kadoya } \\
\qquad(1983)^{8)}\end{array}$} & $44 / \mathrm{M}$ & rt & rt hemiparesis & $\begin{array}{l}\text { subcortical hematoma in } \\
\text { lt temporoparietal lobe }\end{array}$ & $\begin{array}{l}\text { bil ICA occlusion with } \\
\text { moyamoya vessels, } \\
\text { incidental aneurysm }\end{array}$ \\
\hline & $56 / F$ & lt & It hemiparesis & $\begin{array}{l}\text { subcortical hematoma in } \\
\text { rt temporoparietal lobe }\end{array}$ & $\begin{array}{l}\text { bil ICA occlusion with } \\
\text { moyamoya vessels }\end{array}$ \\
\hline $\begin{array}{l}\text { Nakao and Fukumitsu } \\
(1985)^{10)}\end{array}$ & $3 / \mathrm{F}$ & lt & convulsion on $1 t$ & $\begin{array}{l}\text { bil multiple low-density } \\
\text { areas }\end{array}$ & $\begin{array}{l}\text { bil ICA occlusion with } \\
\text { moyamoya vessels }\end{array}$ \\
\hline $\begin{array}{l}\text { Kinjo et al. } \\
(1988)^{6)}\end{array}$ & $16 / \mathrm{F}$ & $\mathrm{rt}$ & rt hemiparesis & $\begin{array}{l}\text { It multiple low-density } \\
\text { areas }\end{array}$ & $\begin{array}{l}\text { bil ICA occlusion with } \\
\text { moyamoya vessels }\end{array}$ \\
\hline Present case & $35 / F$ & $\mathrm{rt}$ & $\begin{array}{l}\text { loss of conscious- } \\
\text { ness }\end{array}$ & normal & $\begin{array}{l}\text { bil ICA occlusion with } \\
\text { moyamoya vessels }\end{array}$ \\
\hline
\end{tabular}

ICA: internal carotid artery.

ing through a persistent primitive artery occurs, especially during a convulsion.

The middle cerebral artery is still in the plexiform stage during obliteration of the primitive presegmental arteries. ${ }^{13)}$ The cerebral vessels at this stage have a similar angiographic appearance to moyamoya disease, suggesting that moyamoya disease and PPTA might have a congenital origin, such as an abnormal development process. However, the etiology of moyamoya disease has not been characterized yet. Suzuki and Takaku ${ }^{14)}$ divided the development into six grades based on an angiographic study. Serial angiography can demonstrate progressive occlusive changes in the intracranial carotid arteries with the development of moyamoya vessels.

The hemodynamic relationship between carotid and vertebrobasilar systems associated with PPTA in progressive occlusive changes in intracranial carotid artery and resultant clinical symptoms cannot be elucidated because such cases are rare. Angiography demonstrated bilateral moyamoya vessels in these six cases, so any tendency for moyamoya vessels to form ipsilateral to a PPTA due to the stealing phenomenon cannot be demonstrated. However, moyamoya disease may be promoted by a PPTA. ${ }^{6 /}$ Other less frequent primitive presegmental arteries have demonstrated only one association of a persistent primitive hypoglossal artery with moyamoya disease. ${ }^{7)}$

The incidence of moyamoya disease is high among the Japanese. However, angiographic studies show a similar incidence of PPTA in Japanese ${ }^{8)}$ and other races. ${ }^{2.9)}$ The hemodynamics of PPTA during progressive occlusive change in the internal carotid artery in moyamoya disease should be re-evaluated to determine its function in the development of moyamoya vessels.

\section{References}

1) Bingham WG, Hayes GT: Persistent carotid-basilar anastomosis. Report of 2 cases. J Neurosurg 18: 398400,1961

2) Eadie MJ, Jamieson KG, Lennon EA: Persisting carotid-basilar anastomosis. J Neurol Sci 1: 501-511, 1964

3) Fields WS: The significance of persistent trigeminal artery. Carotid-basilar anastomosis. Radiology 91: 1096-1101, 1968

4) Handa J, Handa H: Progressive cerebral arterial occlusive disease: Analysis of 27 cases. Neuroradiology 3: 119-133, 1972

5) Huber P: Die A. trigemina primitiva; Betrachtung zur Klinischen Bedeutung der carotido-basilaren Anastomose. Deutsch Z Nervenheilk 181: 612-633, 1961

6) Kinjo T, Mukawa J, Takara E, Nakasone S, Kuda H, Ishikawa Y: Moyamoya disease associated with persistent primitive trigeminal artery: A case report and review of literature. No Shinkei Geka 16: 1107-1112, 1988 (in Japanese)

7) Kurose K, Kishi H, Sadatoh T: Moyamoya disease with persistent primitive hypoglossal artery. Case report. Neurol Med Chir (Tokyo) 29: 528-532, 1989 (in Japanese)

8) Kwak R, Kadoya S: Moyamoya disease associated 
with persistent primitive trigeminal artery. $J$ Neurosurg 59: 166-171, 1983

9) Lie TA: Congenital malformations of the carotid and vertebral arterial systems, including the persistent anastomosis, in Vinken PJ, Bruyn GW (eds): Handbook of Clinical Neurology, vol 12. Amsterdam, North-Holland, 1972, pp 289-339

10) Nakao S, Fukumitsu T: Persistent primitive trigeminal artery in children moyamoya disease. Case report. Shoni No No Shinkei 10: 205-209, 1985 (in Japanese)

11) Nielsen PB, Johnson M: Persistent primitive trigeminal artery demonstrated by vertebral arteriography. $A J R$ 101: 47-51, 1967

12) Otsuki T, Fukawa O, Aihara H: A case of persistent primitive trigeminal artery associated with moyamoya vessels. Rinsho Hoshasen 27: 1453-1456, 1982 (in Japanese)

13) Padget DH: The development of the cranial arteries in the human embryo. Contrib Embryol 32: 207-261, 1948

14) Suzuki J, Takaku A: Cerebrovascular moyamoya disease. Arch Neurol (Chicago) 20: 288-299, 1969

Address reprint requests to: E-C. Tan, M.D., Department of Neurosurgery, Nagoya City Higashi General Hospital, 1-2-23 Wakamizu, Chikusa-ku, Nagoya. 464, Japan. 